\title{
A TRANSMÍdIA E SUA POTÊNCIA NA PRÁTICA DE LEITURA E PRODUÇÃO TEXTUAL
}

\author{
LA TRANSMÍDIA Y SU CAPACIDAD EN LA PRÁCTICA DE LEITURA Y \\ PRODUCCIÓN TEXTUAL
}

\section{THE POTENCIALITY OF TRANSMEDIA NARRATIVE AND THE PRACTICE OF READING AND TEXTUAL PRODUCTION}

\author{
Daniella de Jesus LIMA ${ }^{1}$ \\ Luis Paulo Leopoldo MERCADO ${ }^{2}$ \\ Andrea Cristina VERSUTI ${ }^{3}$
}

\begin{abstract}
RESUMO: Neste artigo refletimos sobre a cultura digital e suas implicações na educação, objetivando discutir a relação entre a narrativa transmídia e a educação, além de apresentar uma metodologia de ensino para os gêneros textuais, a partir da pesquisa bibliográfica e da observação participante com estudantes do curso de comunicação social - jornalismo de uma universidade privada do nordeste brasileiro. Concluímos que o uso de elementos da narrativa transmídia na produção textual apresenta algumas vantagens para o processo educacional.
\end{abstract}

PALAVRAS-CHAVE: Cultura digital. Narrativa transmídia. Gêneros textuais.

RESUMEN:Este artículo refleja sobre una cultura digital y sus implicaciones en la educación. El texto completo de este artículo se refiere a una relación entre una narrativa, una educación y una educación, además de una metodología de enseñanza para todos los géneros textuales, a partir de la investigación bibliográfica y de la observación participativa con los estudiantes del curso de comunicación social jornalismo de una universidad privada del nordeste brasileño. Concluir que el uso de los elementos de la narrativa se transmite en la producción textual.

PALABRAS CLAVE: Cultura digital. Narrativa transmedida. Géneros textuales.

ABSTRACT: In this article we have reflect on the digital culture and its implications in education field, emphasizing the characteristics of the transmedia narrative. The objectives were to discuss the relationship between transmediation and the education, based on the methodology of teaching of textual genres with students of the social

${ }^{1}$ Universidade Federal de Alagoas (UFA), Alagoas - Brasil. Doutoranda em Educação. E-mail: daniellalima90@gmail.com.

${ }^{2}$ Universidade Federal de Alagoas (UFA), Alagoas - Brasil. Professor Titular na graduação em Educação Física e Pedagogia e na Pós-Graduação (Mestrado e Doutorado em Educação.

${ }^{3}$ Universidade de Brasília (UnB). Brasília - Brasil. Professora na área de Educação, Tecnologias e Comunicação do Departamento de Métodos e Técnicas (MTC). 
communication course - journalism of a private university in the brazilian northeast. We also used as methodology the bibliographic research and participant observation. As a result, we conclude that the elements of the transmedia narrative in the students's textual production have presented advantages and improvements for the educational process.

KEYWORDS: Digital culture. Transmedia narrative. Textual genres.

\section{Introdução}

A propagação dos meios de comunicação digitais remodela culturalmente os sujeitos imersos nos espaços sociais. Neste artigo discutiremos o conceito e as características da narrativa transmídia, bem como apresentaremos os resultados de uma aplicação prática dessas características por meio de uma atividade aplicada a estudantes do curso de Comunicação Social - Jornalismo de uma universidade privada, situada no Nordeste brasileiro.

A atividade teve como proposta trabalhar a leitura junto com os sujeitos pesquisados, por meio da leitura do romance Capitães da Areia, de Jorge Amado, e foi trabalhada a produção textual por meio da produção de uma crônica após a leitura do romance. A crônica foi escrita de maneira que desse continuidade à história do romance, expandindo o enredo escrito por Jorge Amado.

Pensamos a inserção de elementos da narrativa transmídia (criação de novas histórias, expansão da narrativa original para outras mídias, coautoria, participação/engajamento com o universo da narrativa) na educação como potência, uma vez que os jovens da cultura atual já são acostumados a construir, por meio da criatividade, personagens e suas histórias, que migram de uma plataforma para outra. Ao fazer uso dos elementos da transmídia mencionados em suas metodologias, por meio dos gêneros textuais, os docentes engajam os estudantes ao conteúdo por meio da realidade em que vivem, além de aprimorarem suas habilidades de leitura, compreensão e escrita.

A escolha do romance Capitães de Areia, usado nesta proposta, resultou das possibilidades deixadas no enredo deste para a expansão da história, de maneira que as histórias da vida dos personagens ficam abertas à imaginação do leitor. Por isso, a atividade planejada, com as características da transmídia de expansão e compartilhamento de narrativas, adequa-se ao romance selecionado. 
O estudo proposto apresentou uma possibilidade metodológica para o ensino de Língua Portuguesa, pois agrega literatura brasileira à leitura e produção textual. Além disso, com a utilização de elementos da trasmídia no processo de ensino e aprendizagem engaja os estudantes em uma realidade presente no cotidiano deles, uma vez que a cultura atual integra os sujeitos à comunicação por meio de ambientes digitais, os quais proporcionam a estes a possibilidade de serem leitores e produtores de conteúdos de forma paralela. Características estas já adotadas pela maioria dos usuários desta cultura, o que aumenta a possibilidade de a proposta deste estudo ser vantajosa para o meio educacional.

Nas características da transmídia, as quais apresentam possibilidades de uma história ser recontada e/ou expandida em diferentes gêneros de texto, linguagens e mídias, pensamos a inserção da narrativa transmídia na educação, a partir do desenvolvimento de uma proposta de leitura e produção de conteúdo, utilizando gêneros textuais, atenta aos elementos da transmídia e dirigida ao romance Capitães da Areia, de Jorge Amado. Por meio dela, os estudantes pesquisados exploraram a criação de histórias paralelas à do romance por intermédio das possibilidades deixadas no decorrer do enredo, além de desenvolverem suas habilidades de leitura, de compreensão e de escrita.

Para a expansão de uma narrativa é necessário a utilização de um gênero textual, entendido como texto/discurso produzido com uma finalidade de comunicação, seja ela qual for. Para a produção de um gênero textual é necessário pensar sobre o momento histórico em que será produzido o enunciado, o público a quem esse enunciado se dirige, o que se quer comunicar para pensar no meio que melhor levará esse enunciado ao "alvo" da comunicação. Assim, refletimos acerca da adequação da crônica à atividade proposta. A crônica é um gênero popular pela linguagem utilizada, o que faz com que seja um gênero acessível a um número maior de sujeitos, uma vez que não sabíamos qual a mídia na qual as narrativas seriam compartilhadas e qual seria o público leitor.

No processo da atividade foi realizada uma oficina com os participantes, na qual foram feitas discussões acerca do enredo do romance, dos conceitos da narrativa transmídia e gêneros textuais, bem como as características do gênero crônica. Além da oficina, os registros de todo o processo foram feitos por meio de um diário de bordo produzido pelos pesquisadores, bem como da realização de um grupo focal com os 
estudantes, ao final do processo. As crônicas foram analisadas de acordo com as características deste gênero, por meio de um instrumento criado pelos pesquisadores.

Neste artigo discutiremos o conceito de narrativa transmídia e as potencialidades para o processo de ensino e aprendizagem, apresentaremos a parte prática do estudo, bem como os resultados alcançados a partir da aplicação da atividade proposta. Apresentaremos também a discussão dos resultados e as impressões de como o uso de elementos da narrativa transmídia na educação pode ser proveitoso tanto para o estudante como para o professor.

\section{A narrativa transmídia e a educação}

Na sociedade atual, a comunicação vai além da fala, leitura e escrita. Em tempos de interação, inovações nos meios de comunicação, troca e compartilhamento de informações contínuas, a cultura dos sujeitos mudou e segue mudando. Nesta cultura, a comunicação acontece por meio de diferentes linguagens presentes em diferentes plataformas de mídia. Essas linguagens surgem com o desenvolvimento das tecnologias digitais da informação e comunicação (TDIC), a partir do desenvolvimento social e das necessidades que surgem por meio desse desenvolvimento.

As plataformas que servem de suporte para a comunicação dos sujeitos imersos na cultura digital, como o Whatsapp, Instagram, Facebook, Google, Youtube e o Twitter disponibilizam diferentes linguagens para a comunicação entre seus usuários, pelo fato de uma única plataforma possibilitar diferentes maneiras de se comunicar e expressar diferentes ideias/pensamentos. Os sujeitos acabam se engajando cada vez mais nessa comunicação, com diversas formas de compartilhar ideias/pensamentos.

Nesta cultura, os sujeitos não estão apenas inseridos no contexto de produção de conteúdos a fim de transpassar informação entre os outros presentes nessa cultura. Estes se engajam no contexto, produzindo e consumindo conteúdos com diferentes finalidades, construindo e compartilhando conhecimento em rede, permitindo trocas contínuas de conteúdos, conhecimentos, informações, gerando aprendizagem, entretenimento, etc.

O contexto da sociedade atual deve ser levado em consideração pelas instituições escolares. Para Citelli (2004, p. 138), "trata-se, pois, de reconhecer que, [...], os fluxos comunicativos e as práticas pedagógicas escolares passaram a ter, por força das presentes circunstâncias históricas, enorme aproximação". Apesar da resistência de 
algumas instituições, é inevitável a inserção dos novos meios comunicativos nas práticas educacionais. Se a cultura muda, o sujeito cultural muda e, consequentemente, as práticas pedagógicas oferecidas a esses sujeitos devem mudar, justapondo-se a essas novas maneiras de comunicação.

O panorama atual da comunicação vivencia uma mudança diferente das vividas anteriormente pela sociedade. Trata-se de uma convergência de linguagens para a construção de discursos compostos pela diversidade de linguagens oferecidas. Em uma única plataforma comunicacional, denominada por Jenkins (2009) como narrativa transmídia, encontra-se texto, vídeo, áudio, foto, cor e luz, disponibilizados em diversas plataformas, como site, blog, cinema, meio impresso ou mesmo em redes sociais. A utilização destas em conjunto edifica uma mensagem final.

Segundo Phillips (2012, p. 13), “[...] as histórias no processo transmidiático são, levemente, entrelaçadas. Cada uma pode ser consumida por si só e o leitor/espectador tem a ideia de que foi lida/assistida uma história completa". Neste estudo enfocaremos o potencial de propostas metodológicas e de elaboração de conteúdos digitalmente expandidos que permitam uma compreensão ampliada de significado, independentemente dos caminhos da leitura e, que, ao mesmo tempo, garantam ao sujeito em contato com uma parte da narrativa compreender o todo satisfatoriamente. Outro fator é a possibilidade da participação, seja com mensagens ou com coautorias de certas histórias complementares ou mesmo da principal.

Para Giovagnoli (2011, p. 17), “[...] fazer transmídia significa permitir múltiplas mídias contarem histórias diferentes, mas todas explorando um tema comum, mesmo que seja experimentado através de diferentes perspectivas da narrativa". O fator mais importante dessa estratégia está na condição de atingir um público que não se satisfaz exclusivamente com um único meio de comunicação e que não está mais disposto em apenas utilizar conteúdos de forma passiva e sim de utilizá-los ativamente, explorando e produzindo.

O projeto estruturado pela narrativa transmídia estabelece, primeiramente, o roteiro e a sua divisão em partes; em seguida define quais plataformas receberão as partes do roteiro; e, finalmente, determina quanto tempo cada plataforma ficará à disposição do público e como ele poderá participar e/ou articular as narrativas.

Além da divisão de uma história e disponibilização de suas partes em diferentes plataformas de mídia, a narrativa transmídia pode ser construída a partir de uma história primária que deixa possibilidades de expansão no decorrer de sua narrativa. Dessa 
maneira, o próprio autor ou os leitores/consumidores podem expandir a história, criando narrativas paralelas a esta e sendo disponibilizadas em diferentes mídias. No caso dos leitores/consumidores, ao produzirem histórias expansivas para estas, se tornariam coautores do produto cultural.

Para Moraes e Santos (2013, p. 22), a narrativa transmídia no entretenimento, na comunicação mercadológica, no jornalismo ou na educação pode ser considerada uma potência para o engajamento do sujeito no universo do produto cultural que está em diferentes plataformas ou que está sendo expandido e disponibilizado em diferentes plataformas: "os atores do processo comunicacional deixam de ser emissores e receptores e são considerados interlocutores e produtores de uma narrativa complexa".

Com as mudanças culturais, a partir das quais os sujeitos deixam de ser uma audiência passiva e passam a aderir à característica de sujeitos produtores de conteúdos, pensamos na inserção da transmidiação na educação. Uma vez que, no contexto da cultura digital, para que o processo de ensino e de aprendizagem possa ser significativo, eficaz e efetivo, as instituições devem desenvolver um sistema acadêmico moderno, que esteja de acordo com as necessidades atuais do ensino e da aprendizagem, bem como dos sujeitos aprendizes. Para isso, é imprescindível o uso de TDIC, mídias e metodologias que "conversem" com a forma de aprendizagem dos sujeitos inseridos nessa cultura digital. (FAVA, 2014).

No contexto em que os sujeitos culturais estão inseridos, os elementos da transmídia (criação de novas histórias, expansão da narrativa original para outras mídias, coautoria, participação/engajamento com o universo da narrativa) fazem parte de seus cotidianos. Vivem, hoje, em constante interação com o mundo, consumindo e produzindo conteúdos de diversas espécies e para diversos fins. A educação é item inerente na vida dos sujeitos, e esta deve se adequar à realidade do contexto mencionado, pois é a realidade atual.

Propomos a inserção dessa realidade no ensino e aprendizagem, dando ênfase ao ensino de Língua Portuguesa, relacionando o conteúdo gêneros textuais, elementos da transmídia e literatura. A sociedade de educação e aprendizagem contínua associa-se ao descentramento, conhecimento além do livro, deslocalização, a aprendizagem além dos muros da escola e a destemporalização, pois não há tempo para aprender. (BARBERO, 2014).

Partindo dos pressupostos definidos por Massarolo e Mesquita (2013), não só no ambiente escolar, mas em todo o contexto social, a migração dos sujeitos estudantes, ou 
não, por ambientes caracterizados pela mobilidade, interatividade e a colaboração constante, além de uma nova cultura para o ensino e a aprendizagem, atrelando a participação dos estudantes em processos de criação de narrativas, seja baseada em uma narrativa fonte ou não.

\section{Teoria na prática: o uso de elementos da narrativa transmídia no contexto educacional}

Apresentaremos os resultados alcançados por meio de uma pesquisa feita com estudantes do curso de Comunicação Social - Jornalismo de uma universidade privada do Nordeste brasileiro. A pesquisa foi realizada a partir de uma atividade de leitura e produção de texto, na qual os sujeitos leram o romance Capitães da Areia (AMADO, 2009), e com essa leitura escreveram uma crônica expandindo a história do romance por meio de outro gênero, a crônica, disponibilizada em outra mídia, diferente do romance, que relaciona a proposta da atividade com a transmídia.

As crônicas produzidas mantiveram as características do enredo, que fazem parte do universo narrativo do romance Capitães de Areia, tornando a expansão proposta o princípio de construção de uma narrativa transmídia. Falamos em princípio de construção pelo fato de a história dos Capitães da Areia não ser uma narrativa transmídia, pois a história do romance foi apenas reproduzida em um longa-metragem. Além disso, há também a produção de histórias de fãs, as fanfics, baseadas no enredo original, mas que não é o suficiente para os Capitães da Areia ser considerada narrativa transmídia.

Utilizamos a observação participante como intervenção metodológica no ensino de gêneros textuais, nesse caso a crônica, e desenvolvimento das habilidades de leitura, de compreensão e de escrita, etapas nas quais os pesquisadores estiveram intervindo a todo momento. A partir da observação participante, foi construído um diário de bordo, a fim de registrar, com detalhes, todas as etapas do processo.

Foi feito um grupo focal com os estudantes no final do processo, para saber as impressões dos sujeitos com relação à aprendizagem do gênero desenvolvido, bem como o aprimoramento das habilidades comunicativas de leitura, de compreensão e de escrita. As etapas do estudo foram:

$1^{\mathrm{o}}$ momento (presencial) - foi feito o primeiro contato com os estudantes em sala de aula, no qual os apresentamos à proposta da atividade. Explicamos todo o processo da 
atividade, o que iria acontecer em cada uma das etapas. Ao final da explicação, foi solicitado que os estudantes fizessem a leitura do romance Capitães da Areia até o próximo encontro, quinze dias depois.

$2^{\circ}$ momento (presencial) - foi realizada uma oficina junto com os estudantes, na qual os pesquisadores explanaram dialogicamente acerca do conceito da narrativa transmídia e dos gêneros textuais (enfatizando a crônica). Durante a explanação, os estudantes tiraram várias dúvidas, principalmente sobre a narrativa transmídia, pois este era um termo novo para todos. Destacaram que têm contato com esses universos narrativos presentes em diferentes mídias no dia a dia, mas não conheciam a denominação. Além disso, discutimos o enredo do romance Capitães da Areia, já lido por eles, e suas possibilidades de expansão por meio das brechas deixadas pelo autor. Explicamos novamente a proposta da atividade e finalizamos a oficina sanando dúvidas dos estudantes.

$3^{\circ}$ momento (presencial) - este encontro teve como objetivo sanar dúvidas dos estudantes acerca da discussão feita no momento anterior. Aconteceu uma semana após a realização da oficina. Neste encontro, os pesquisadores solicitaram o contato do WhatsApp dos estudantes e criaram um grupo neste aplicativo, a fim de manter contato durante todo o período da produção (4 semanas).

$4^{\mathrm{o}}$ momento (via WhatsApp) - durante o período de quatro semanas, o contato dos pesquisadores com os estudantes foi feito a distância. Durante esse período, os estudantes produziram a crônica expandindo a história do romance que eles fizeram a leitura. A expansão de uma narrativa, por meio de um gênero textual diferente do que está disponibilizada a narrativa original e disponibilizada em uma mídia, também diferente, é o que está relacionada à narrativa transmídia.

$5^{\circ}$ momento (presencial) - o último momento da atividade aconteceu com a entrega das produções dos estudantes para os pesquisadores e com a realização do grupo focal junto com estes, com o intuito de coletarmos informações sobre as impressões dos estudantes acerca da atividade realizada. Neste foram feitos questionamentos acerca da experiência que os estudantes tiveram, enfatizando a aprendizagem com relação aos gêneros textuais e aprimoramento das habilidades comunicativas de leitura, compreensão e escrita.

$\mathrm{Na}$ análise dos registros do processo no diário de bordo, constatamos que os participantes não interagiram durante o desenvolvimento da atividade, momento referente às quatro semanas destinadas à produção da crônica. A interação aconteceu apenas no momento de discussão presencial, na oficina que ocorreu no início do 
processo. O uso do aplicativo não foi visto pelos participantes como meio de discussão dos conteúdos abordados na atividade.

$\mathrm{Na}$ discussão do grupo focal foram abordadas as seguintes temáticas: metodologia de ensino de gêneros textuais por meio dos elementos utilizados da narrativa transmídia e aprimoramento das habilidades de leitura, compreensão e escrita, referentes às categorias de análise. A discussão durou cerca de 45 minutos e todos os sujeitos participaram ativamente, respondendo a todos os questionamentos.

\section{Aprendizagem do gênero textual crônica}

Nesta categoria, os questionamentos feitos aos sujeitos pesquisados estão relacionados à metodologia utilizada para a realização da atividade, bem como à forma que esta influenciou na aprendizagem deles acerca do gênero textual trabalhado. Por meio das respostas dadas pelos sujeitos, a atividade elaborada a partir de elementos da transmídia ajudou os estudantes na aprendizagem do gênero textual crônica. Todos apontaram que a prática da produção de um texto "seu" ajudou na aprendizagem, na preocupação de construir o gênero.

Para ilustrar a ideia de como a atividade contribuiu para a aprendizagem do gênero textual crônica, seguem trechos da fala de dois estudantes. O estudante D enfatiza, "pelo fato de a gente ler, fazer, usar a transmídia para fazer um texto, você vai prestar atenção nas características. Então eu aprendi a fazer a crônica por causa disso, pelo fato de eu ter que analisar as características e colocar aquilo no meu texto".

Nesta fala, a ideia de ter que escrever um texto autoral, há uma preocupação em ir em busca de como deve ser feito, o que representa a ideia de coautoria, um dos elementos da transmídia citados para a elaboração da atividade. Pelo fato de o sujeito criar um texto autoral, baseado em um outro conteúdo, este terá uma maior preocupação na construção desse texto. O que influencia na aprendizagem do gênero que está sendo construído, pois na medida em que o sujeito investiga sobre o gênero, está agregando conhecimento acerca deste.

Outro aspecto apresentado por um dos sujeitos foi a prática, pois quando se pratica, aprende-se mais do que quando se é apresentado à teoria. Segundo o estudante E, na Educação Básica tem-se uma maior preocupação com a teoria e reprodução desta nos exames aplicados nas avaliações. Afirma que nunca tinha feito uma crônica, apenas ouvia falar, mas não conhecia as suas características e função. 
Com certeza eu achei muito importante, porque na escola a gente aprende muito a teoria, decora, faz a prova e vai embora, e aí nunca produz, eu por exemplo nunca tinha produzido uma crônica, nunca. Mas eu já li vários livros de crônica, mas não pegava essa ideia de que a crônica tem uma crítica social, alguma coisa assim. Eu não via isso, eu lia sem saber que tinha essas coisas, e aí com isso, me ajudou muito a ver essas características da crônica para produzir e até parei para pensar nas crônicas que eu li há muito tempo atrás, que eu não via o lado mais elaborado por trás dela. Eu achei muito interessante, achei legal. (Estudante E).

Para a aprendizagem de gêneros textuais, a prática destes é uma alternativa que apresenta vantagem, segundo os sujeitos pesquisados. Acreditamos que a primazia da teoria em relação à prática é um fator que pode afetar, de maneira negativa, na aprendizagem efetiva dos gêneros textuais por parte dos estudantes.

\section{Aprimoramento da habilidade de leitura}

A categoria de análise relacionada à habilidade de leitura dos sujeitos contempla a ideia de que a partir do desenvolvimento dessa atividade houve algum aprimoramento da habilidade de leitura dos participantes. Para contemplar essa categoria, foram levantados questionamentos acerca da habilidade de leitura deles; enfatizamos o aprimoramento desta, ou não, por meio da atividade desenvolvida.

$\mathrm{Na}$ análise das respostas dadas a esta pergunta, chega-se a ideia de que a atividade desenvolvida aprimorou a habilidade de leitura dos estudantes para o gênero textual crônica. Todos os participantes afirmaram que para a crônica a leitura melhorou muito, mas só para esse gênero, como afirma o estudante C.

[...] a leitura não é mais superficial, você vai prestar cada vez mais, tipo toda vez que eu for ler uma crônica agora eu não vou só ler, eu vou prestar atenção em tudo aquilo que eu trabalhei para produzir essa crônica, então é uma leitura muito mais profunda e detalhada que a gente que fazer para produzir a crônica.

Três dos cinco sujeitos afirmam que se essa atividade fosse feita com qualquer outro gênero traria vantagens para a leitura deste também. Segundo os sujeitos participantes, esta produção pode ser feita com qualquer outro gênero que trará contribuição para a habilidade de leitura, mais especificamente para a leitura do gênero desenvolvido, que no caso desta pesquisa foi a crônica. 
Acho que melhorou muito para a crônica, mas também só para a crônica e eu acho que poderia e deveria ser para todos os tipos de texto a nível de fundamental, médio, superior, porque é muito mais simples aprender assim, a gente não precisou passar horas e horas estudando o que é uma crônica, decorando quais são as características. (Estudante E).

A partir da análise dessas ideias, chegamos ao ponto de que o desenvolvimento da atividade contribuiu para o aprimoramento da habilidade de leitura, mais especificamente para a leitura do gênero que foi desenvolvido. E ainda, que a atividade pode ser adaptada para se trabalhar com qualquer outro gênero textual.

\section{Aprimoramento da habilidade de compreensão}

$\mathrm{Na}$ discussão referente a esta categoria, quatro dos cinco participantes afirmaram que a atividade ajudou para o aprimoramento da habilidade de compreensão, mas apenas para a compreensão da crônica. Afirmaram que se a atividade fosse desenvolvida com outros gêneros textuais, ampliar-se-ia esse aprimoramento para outros textos. Percebemos isso ao ler parte da fala do estudante A: "Para mim sim, mas voltada para a compreensão de crônicas. Concordo com os outros que se fosse aplicada a atividade com outros gêneros, melhoraria ainda mais essa e outras habilidades”.

Com relação ao aprimoramento das habilidades comunicativas de leitura e compreensão, as vantagens estão voltadas apenas para o gênero trabalhado na prática. Em meio a essa ideia apresentada pelos cinco sujeitos, um afirma que a habilidade de interpretação é adquirida e aprimorada com a prática, não se prendendo apenas no gênero que se lê ou escreve no momento.

[...] o objetivo é que se isso fosse aplicado com os alunos, se eles iam adquirir a habilidade de interpretação. Eu acredito que sim, porque não só nessa atividade, mas se você botar alguém para ler o livro, ela vai adquirir uma habilidade de interpretação, [...] com certeza, porque uma pessoa que não tem costume de ler um livro e faz essa atividade ela já vai estar lendo o livro, então ela vai adquirir a habilidade de interpretação. (Estudante D).

Esses sujeitos, por estarem tão condicionados à falta de prática de leitura e produção de texto, acabam por ficar presos quando se fala em produzir um gênero textual. Por não terem essa rotina, ficam presos aos fatores que englobam aquele único gênero trabalhado, fazendo com que tenham a ideia de que essas habilidades 
comunicativas estão atreladas, especificamente, ao gênero. $O$ único que teve uma visão diferente foi o estudante $\mathrm{D}$, que menciona que a habilidade de interpretação/compreensão está relacionada à prática.

\section{Aprimoramento da habilidade de escrita}

Nesta categoria, todos os sujeitos afirmaram que a habilidade de escrita foi aprimorada e não só para a crônica. Alguns limitaram-se a alguns tipos de textos, mas, diferente das respostas para as outras duas habilidades, desprenderam-se da ideia de ter só aprimorado a habilidade para a crônica.

Apesar de ter sido praticada a escrita de apenas um gênero textual, isso contribui para a escrita de outros textos. Quando o estudante B ressalta que "mesmo que isso fique um pouco fragmentado", sabemos que esses fragmentos são os diferentes tipos e gêneros de textos. Segundo esse estudante, a escrita é uma habilidade que deve ser aprimorada por parte, e a cada parte adicionada, se aprimorará esta habilidade comunicativa.

[...] realmente melhora sobre a escrita, justamente por treinar, se você treina você acaba aprendendo [...]. Qualquer texto que eu for pegar agora para escrever, pode ser que eu não saiba escrever exatamente como o gênero pede, mas por eu já ter escrito, geralmente a gente só escreve texto dissertativo e por agora eu ter escrito uma crônica, realmente melhora a parte da escrita. (Estudante A).

Percebemos a compatibilidade das respostas dos dois estudantes; o mesmo acontece com as respostas dadas pelos outros três. Com relação à habilidade de escrita, todos defendem a ideia de que com a prática esta é aprimorada. Independente do gênero trabalhado, a escrita em si acaba sendo melhorada com a prática de produção de texto. Esse estudante ressalta ainda que talvez não consiga escrever outro gênero, contemplando suas características.

Por meio da análise feita das falas dos estudantes, percebemos que o desenvolvimento da atividade, fazendo uso de elementos da transmídia para construir um gênero textual, contribuiu para a aprendizagem do gênero trabalhado. Aprimorou também as habilidades comunicativas, principalmente a habilidade de escrita, uma vez que parte dos sujeitos afirmaram que o aprimoramento das habilidades de leitura e compreensão ficaram presas ao gênero textual crônica, inclusive, alguns afirmaram isso 
na estabilidade de nível apresentada nos questionários respondidos antes e após a prática de leitura e produção.

\section{Capitães da Areia expandido: breve análise das produções}

Para analisar as produções dos estudantes listamos dez características do gênero textual crônica a fim de verificar quantas destas cada uma das produções atendeu, bem como realizamos uma análise do conteúdo geral. Para listar as características no gênero utilizamos o aporte teórico de Moisés (1994). As características apresentadas pelo autor para o gênero crônica são: Texto curto; Texto construído por meio da subjetividade do autor; Apresenta a visão do autor sobre o que se está relatando; Apresenta semelhança com um monodiálogo ou apresenta característica dialógica; Apresenta linguagem direta, espontânea e de fácil apreensão; Faz referência a algum tema do cotidiano; Apresenta estilo ágil, simples e poético, ou seja, coloquial e literário; Apresenta personagens; Faz uso de ambiguidade para tratar da temática; Apresenta traços de ironia ao tratar da temática. Apresentaremos a seguir as análises feitas para cada produção:

Estudante $\mathrm{A}$ - o estudante $\mathrm{A}$ atendeu a quatro das dez características do gênero listadas. O nível de conhecimento desse estudante acerca das características da crônica está em nível intermediário. Durante os momentos presenciais da atividade, a estudante A tirou apenas algumas dúvidas e não se manifestou em nenhum momento no grupo do WhatsApp. O texto deste estudante foi construído por meio da subjetividade do autor, fazendo uso de uma linguagem simples para apresentar uma temática do cotidiano (abandono de jovens). O texto, de caráter narrativo, utilizou de personagens para contar o fato.

Estudante B - este atendeu a sete das dez características do gênero listadas, caracterizando um bom conhecimento do gênero textual crônica. Durante o processo, o estudante B interagiu tirando dúvidas e discutindo nos encontros presenciais, porém, nos contatos via WhatsApp não se manifestou em nenhum momento. O texto foi construído por meio da subjetividade do autor, mostrando sua visão sobre o que está sendo relatado, com características de um monodiálogo. Apresenta uma linguagem simples, pondo em evidência um tema do cotidiano (abandono de crianças). Uma característica muito importante da crônica não foi percebida no texto do estudante $B$, 
que é a presença de crítica/ironia ao que está sendo relatado; o fato é narrado como acontece, mas não é possível perceber a presença de uma crítica pessoal a isso.

Estudante C - este atendeu a cinco das dez características do gênero listadas, caracterizando um conhecimento intermediário acerca do gênero trabalhado. $\mathrm{O}$ estudante C não interagiu durante a atividade, apenas ao final, no grupo focal. Tanto no encontro presencial como nos contatos feitos via WhatsApp, este sujeito não se manifestou em momento algum. $\mathrm{O}$ texto do estudante $\mathrm{C}$ foi construído a partir da subjetividade do autor, por meio de uma linguagem simples, com estilo poético. Algumas das principais características da crônica foram "esquecidas" pelo estudante C, como a semelhança com um monodiálogo, apresentação de um tema do cotidiano, proporcionando uma crítica a este. A falta desses elementos característicos do gênero crônica possivelmente está atrelada à falta de interação do estudante durante o momento presencial em que foram apresentadas todas as características, bem como na falta de contato com a apresentação de dúvidas durante a produção, fatores que podem ter comprometido esta.

Estudante D - o estudante D atendeu a oito das dez características do gênero listadas, apresentando um bom domínio do gênero trabalhado. Este estudante participou bastante das discussões no encontro presencial; nos contatos via WhatsApp, como aconteceu no geral, o estudante tirou dúvidas acerca de datas e parte estrutural da produção. Dúvidas acerca dos conteúdos foram apresentadas somente na oficina, que foi o encontro presencial. No texto produzido pelo estudante $D$, quase todas as características da crônica foram atendidas. Porém, uma das que não foram atendidas está relacionada à crítica/ironia feita ao tema tratado. $\mathrm{O}$ autor apresenta em forma de narrativa uma temática do cotidiano, mas não apresenta uma crítica pessoal a este fato, o que é característica essencial nesse gênero textual. Mesmo com essa falha, o texto foi bem estruturado de acordo com a proposta da atividade e atendeu a quase todas as características apresentadas por Moisés (1994).

Estudante $\mathrm{E}$ - o estudante $\mathrm{E}$ atendeu a nove das dez características do gênero listadas e foi o que teve melhor aproveitamento com relação à produção e atendimento das características do gênero. Durante o processo, este estudante foi o que mais participou, desde o início, tirando dúvidas e participando das discussões no encontro presencial, o que pode ser considerado fator relevante para o bom desempenho na construção do texto. Na produção do estudante E só não foi atendida uma característica 
do gênero textual crônica: a presença de ambiguidade para tratar da temática não foi identificada no texto.

Verificamos que, no geral, o aproveitamento dos estudantes foi bom, com relação à produção do gênero proposto. Mais da metade tive um nível bom na produção, o que consideramos satisfatório no processo.

\section{Considerações finais}

As TDIC apresentam caminhos para a comunicação entre os sujeitos imersos na realidade do contexto da cultura digital. Estes sujeitos possuem diferentes e, ainda, mais maneiras de se comunicar com outros, independente de lugar e do tempo. É necessário apenas possuir um aparelho de tecnologia móvel e acesso à internet, o que modifica os hábitos desses sujeitos em todas as esferas sociais, do trabalho, da família, das amizades.

Dentre essas mudanças de hábitos na comunicação, destaca-se o consumo, compartilhamento e criação de conteúdos, sejam estes de qualquer espécie. Na cultura digital, todo conteúdo disponibilizado ao público, seja digital ou não, está sujeito a essa tríade mencionada. Este pode ser consumido, compartilhado e, ainda, criado ou recriado pelos usuários da internet, o que faz com que os sujeitos construam e compartilhem conhecimento em uma aprendizagem constante.

Diante dessa realidade, aplicamos uma metodologia de ensino e aprendizagem de gêneros textuais, mais especificamente a crônica. Para isso, levamos em consideração a realidade do contexto da cultura digital, no intuito de engajar os sujeitos pesquisados no processo, fazendo com que tivessem uma melhor aprendizagem do gênero e, ao mesmo tempo, aprimorassem as habilidades comunicativas de leitura, de compreensão e de escrita. Os resultados dessa prática foram alcançados a partir de diário de bordo, avaliação das crônicas produzidas e por meio dos depoimentos dados pelos sujeitos no grupo focal.

No desenvolvimento deste trabalho, mostramos que a narrativa transmídia, elemento presente na cultura digital, apresenta caminhos inovadores para o processo de ensino e aprendizagem. Ao final do estudo, percebeu-se que houve aprendizagem do gênero textual crônica, por meio da criação da uma extensão da narrativa do romance Capitães da Areia, utilizando o gênero crônica. 
Além da aprendizagem do gênero textual crônica, verificamos o aprimoramento das habilidades comunicativas de leitura, de compreensão e de escrita. A partir da relação feita entre os resultados obtidos com esta investigação qualitativa, segundo os estudantes, a atividade contribuiu para o aprimoramento das habilidades de leitura e de compreensão do gênero textual crônica.

Elucidamos que a metodologia utilizada na atividade para a aprendizagem de gêneros textuais e aprimoramento das habilidades comunicativas é válida. Tratamos de gêneros textuais no geral, porque a atividade feita com a crônica pode ser adequada para ser feita com qualquer outro gênero. Com os dados coletados, percebemos que a aprendizagem e entendimento dos estudantes acerca do gênero crônica aconteceram. Com relação às habilidades comunicativas, estas foram aprimoradas, mesmo com algumas afirmações de que o aprimoramento ficou restrito ao gênero trabalhado.

A partir da utilização de elementos da narrativa transmídia na educação, o professor pode estimular o estudante a ser sujeito autor da sua própria aprendizagem. À medida que este tiver a liberdade de criar e recriar conteúdos baseados em uma narrativa "fonte", estará adquirindo autonomia para tornar-se mais independente no processo de ensino e aprendizagem, o que é uma característica proporcionada pelas mídias para os sujeitos, já que essas mídias conquistam e esses sujeitos aprendem sobre as informações que consomem e muitas vezes produz/(co)produz nestas. Há vantagens em utilizá-las, por meio da narrativa transmídia, para a aprendizagem no espaço educacional.

Com relação à aprendizagem do gênero textual crônica, em todos os resultados apresentados houve aprendizagem por parte dos sujeitos. Isso, pelo fato de a atividade não ficar circunscrita apenas na apresentação da teoria e, sim, proporcionar ao sujeito a possibilidade de construir o próprio gênero, tendo como base a narrativa original.

Além da interação que há durante o processo e a autonomia dos sujeitos para construir o próprio conhecimento, outro fator que merece destaque e que contribuiu para o desenvolvimento das produções é a (co)autoria. Ao construir um texto autoral, o sujeito tem uma maior preocupação em atender as demandas, como foi mencionado por um dos estudantes no grupo focal.

E, com relação às habilidades comunicativas de leitura, compreensão e escrita, os estudantes aprimoraram estas no processo da atividade por meio da prática. A atividade contribuiu para o aprimoramento da leitura e da compreensão para o gênero textual crônica. Acreditávamos que a prática aprimoraria essas habilidades para qualquer tipo ou gênero de texto, mas não foi o que percebemos a partir dos discursos 
dos estudantes no grupo focal. Já acerca da escrita, concluímos que esta foi aprimorada para diversos tipos e gêneros de textos, confirmando o que foi apresentado no pressuposto.

Contudo, defendemos que os elementos da narrativa transmídia: criação de novas histórias, expansão da narrativa original para outras mídias, coautoria e participação/engajamento com o universo da narrativa, se inseridas no contexto educacional, traz vantagens para o processo ensino e aprendizagem, uma vez que estes elementos estão presentes no contexto atual de interação e colaboração dos sujeitos, isto é, na cultura digital em que estão inseridos esses sujeitos.

\section{REFERENCIAS}

AMADO, Jorge. Capitães da areia. São Paulo: Companhia das Letras, 2009.

BARBERO, Jesús Martín. A comunicação na educação. São Paulo: Contexto, 2014.

CITELLI, Adilson. Comunicação e educação: a linguagem em movimento. 3. ed. São Paulo: Senac São Paulo, 2004.

FAVA, Rui. Educação 3.0: aplicando o PDCA nas instituições de ensino. São Paulo: Saraiva, 2014.

GIOVAGNOLI, Max. Transmedia storytelling: imagery, shapes e techniques. Pittsburgh: ETC Press, 2011.

JENKINS, Henry. Cultura da convergência. 2. ed. São Paulo: Aleph, 2009.

MASSAROLO, João Carlos; MESQUITA, Dario. Narrativa transmídia e a educação: panorama e perspectivas. Ensino Superior Unicamp, Especial, p. 34-42, 2013.

MOISÉS, Massaud. A criação literária: prosa 2. 15. ed. São Paulo: Cultrix, 1994.

MORAES, Elizabeth Goncaloes; SANTOS, Marli. O jornalismo como narrativa transmídia: reflexões possíveis. In: RENÓ, Denis.; CAMPALANS, Carolina; RUIZ, Sandra; GOSCIOLA, Vicente. ed(s). Periodismo transmedia: miradas múltiples. Bogotá: Editorial Universidad del Rosário. Escuela de Ciencias Humanas, 2013. p. 2134.

PHILLIPS, Andrea. A creator's guide to transmedia storytelling: how to captivate and engage audiences across multiple platforms. New York: McGraw-Hill: 2012. 


\section{Como referenciar este artigo}

LIMA, Daniella de Jesus Lima.; MERCADO, Luis Paulo Leopoldo.; VERSUTI, Andrea Cristina. A transmídia e sua potência na prática de leitura e produção textual. Revista Ibero-Americana de Estudos em Educação, Araraquara, v. 12, n. esp. 2, p. 1313-1330 ago./2017. Disponível em: <http://dx.doi.org/10.21723/riaee.v12.n.esp.2.10299>. E-ISSN: 1982-5587.

Submetido em: 10/03/2017

Aprovação final em: 09/08/2017 